\title{
Producción forrajera y semillas de Panicum virgatum, Tripsacum dactyloides y Sporobolus airoides en Tulancingo, Hidalgo
}

\author{
Forage and seed production of Panicum virgatum, Tripsacum dactyloides and \\ Sporobolus airoides in Tulancingo, Hidalgo
}

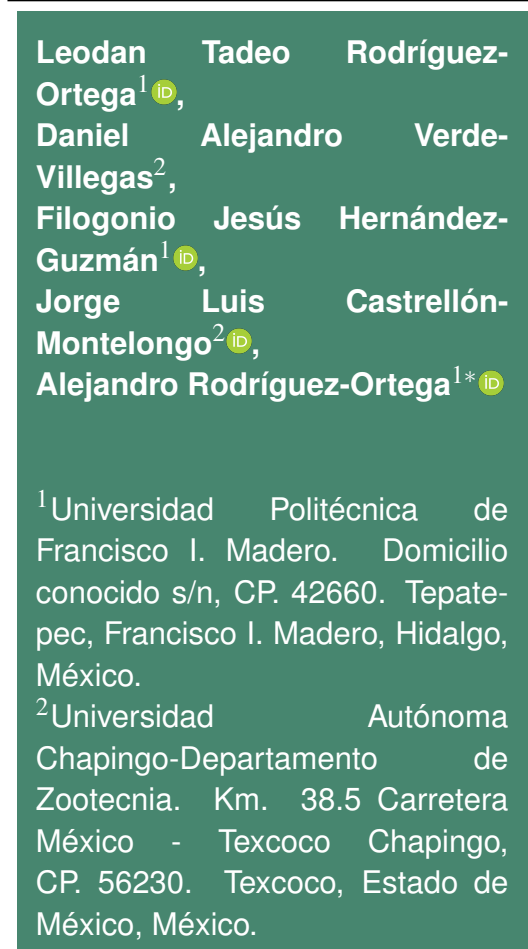

${ }^{*}$ Autor de correspondencia: filomanhernandez@gmail.com

\section{Artículo científico}

Recibido: 06 de marzo 2021

Aceptado: 06 de octubre 2021

Como citar: Rodríguez-

Ortega LT, Verde-Villegas

DA, Hernández-Guzmán FJ,

Castrellón-Montelongo

JL,

Rodríguez-Ortega A (2021)

Producción forrajera y semillas

de Panicum virgatum, Tripsacum

dactyloides y Sporobolus airoides en Tulancingo, Hidalgo. Ecosistemas y Recursos Agropecuarios Núm. Esp. II: e2861.

DOI:
RESUMEN. Ante la necesidad de transferir tecnología de pastos del semiárido mexicano de alto potencial forrajero se evalúo al establecimiento pasto switchgrass (Panicum virgatum), pasto maicero (Tripsacum dactyloides) y zacatón alcalino (Sporobolus airoides): producción de forraje, densidad poblacional de tallos, producción de semillas, así como caracterización física y fisiológica de semillas. El estudio se realizó en dos ciclos de abril a agosto y de agosto a diciembre de 2020 en condiciones de riego a 8333 plantas ha ${ }^{-1}$. Los tratamientos fueron tres pastos, en campo, distribuidos en Bloques Completamente al Azar, y en laboratorio, Completamente al Azar (Tukey $\alpha=0.05$ ). El rendimiento mayor de forraje se observó en switchgrass (3.59 t MS ha ${ }^{-1}, \mathrm{P}<0.0001$ ), y superó a pasto maicero y zacatón alcalino en 3.0 y 4.9 veces, respectivamente. La mayor densidad poblacional de tallos se presentó en pasto maicero con 216 tallos planta ${ }^{-1}$ y superó a switchgrass y zacatón alcalino en 1.15 y 2.6 veces $(P<0.0001)$, respectivamente. La mayor producción de unidades de dispersión ocurrió en pasto maicero $177 \mathrm{~kg} \mathrm{ha}^{-1}$; similar a switchgrass con $147 \mathrm{~kg} \mathrm{ha}^{-1}(P>0.05)$, sin embargo, cúpulas con incipiente pureza física $(0.79 \%)$. La viabilidad disminuyó a mayor tamaño de cariópside entre especie, por tanto, mayor cantidad de semilla pura viable se determinó en zacatón alcalino (12.3 $\left.\mathrm{kg} \mathrm{ha}^{-1}\right)$ y superó a switchgrass en 1.3 veces. Switchgrass es una alternativa forrajera por buen rendimiento de forraje y semilla al establecimiento. El pasto maicero se mostró como una alternativa viable para su propagación con material vegetal.

Palabras clave: Diásporas, cúpulas, establecimiento de pastos, altiplano hidalguense.

ABSTRACT. Given the need to transfer grasses of the mexican semiarid of hight forage potential were evaluated switchgrass (Panicum virgatum), estearn gamagrass (Tripsacum dactyloides) and alkali sacaton (Sporobolus airoides) in production of forage, tiller population density, seed production as well as physical and physiological characterization of seeds. The study was carried out in two cycles from april to august and from august to december under irrigation conditions at 8333 plants ha ${ }^{-1}$. The treatments were three grasses, on field, Completely Random Blocks and in laboratory, Completely Random (Tukey $\alpha=0.05$ ). The highest forage yield was observed in switchgrass (3.59 t DM ha ${ }^{-1}, \mathrm{P}<0.0001$ ), and surpassed eastern gamagrass and alkali sacaton in 3.0 and 4.9 times, respectively. The highest population density of tillers was seed eastern gamagrass with 216 tillers plant $^{-1}$ and surpassed switchgrass and alkali sacaton by 1.15 and 2.6 times, respectively $(P<0.0001)$. The highest production of dispersal units occurred in eastern gamagrass $177 \mathrm{~kg} \mathrm{ha}^{-1}$; similar to switchgrass with $147 \mathrm{~kg} \mathrm{ha}^{-1}(\mathrm{P}>0.05)$, however, cupules with incipient physical purity $(0.79 \%)$. Viability decreased with a larger caryopsis size, therefore, a greater quantity of viable pure seed was determined in alkali sacaton $\left(12.3 \mathrm{~kg} \mathrm{ha}^{-1}\right)$ and surpassed switchgrass by 1.3 times. Switchgrass is a forage alternative as it has good forage and seed yield in the first year of establishment. Eastern gamagrass is forage viable alternative to be propagated by plant material alive.

Key words: Diaspores, cupules, grasses establishment, Hidalgo highland. 


\section{INTRODUCCIÓN}

La escasa transferencia tecnológica en el agro mexicano en los últimos años se ha estado manifestando en baja productividad en las diversas regiones de Hidalgo (Ayala-Garay et al. 2013). Los pastos (Poaceae) son una alternativa forrajera que pueden aprovechar desde $20 \mathrm{~mm}$ de lluvia para rebrotar; ante la escases y mala distribución de lluvia en zonas semiáridas (Velázquez et al. 2014).

En México se encuentran distribuidos recursos genéticos de switchgrass, pasto maicero y zacatón alcalino. El pasto switchgrass (Panicum virgatum $\mathrm{L}$.) es un pasto perenne $\mathrm{C}_{4}$. Al respecto, Marra et al. (2013) reporta que el primer año de producción se tienen rendimientos promedios de $2359 \mathrm{~kg} \mathrm{MS} \mathrm{ha}^{-1}$, mientras que Ra et al. (2012) reportan $9100 \mathrm{~kg}$ $\mathrm{MS} \mathrm{ha}^{-1}$. En otro estudio realizado en switchgrass por Taylor et al. (2019), al evaluar 333 genotipos en temporal a $204 \mathrm{msnm}$, a distancia de $0.9 \mathrm{~m}$ entre plantas y fertilizadas con $100 \mathrm{~kg} \mathrm{~N} \mathrm{ha}^{-1}$; se tuvieron alturas de plantas de 39 a $141 \mathrm{~cm}(83 \mathrm{~cm}$ en promedio), diámetro de corona de 9.3 a $63 \mathrm{~cm}(35 \mathrm{~cm}$ promedio). Sobre la densidad poblacional de tallos en switchgrass Min et al. (2017) reportan en 22 genotipos en macetas en invernadero en el primer año de 11 a 24 tallos por planta y altura de planta de 110 a $195 \mathrm{~cm}$, mientras la producción de semilla de switchgrass según Lee et al. (2009) es de $108 \mathrm{~kg} \mathrm{ha}^{-1}$ en praderas de alturas sobre el nivel del mar inferior a 1 $000 \mathrm{~m}$. El pasto maicero [Tripsacum dactyloides (L.) L.] es un pasto $C_{4}$ perenne distribuido en el Noreste mexicano y Este de E.U., utilizado debido a su buena palatabilidad (Coblentz et al. 2010). La producción de forraje de $T$. dactyloides reportada por Krizek et al. (2003) en seis sitios de EUA en condiciones de temporal del $1^{e r}$ al $3^{e r}$ año, fue de 2288,4469 y 6007 $\mathrm{kg} \mathrm{MS} \mathrm{ha}^{-1}$ a densidad de 15000 plantas ha ${ }^{-1}$, con diámetro de corona de 11.3 a $25.9 \mathrm{~cm}$ (Springer et al. 2003). Para el número total de tallos, se reportan 200 tallos $\mathrm{m}^{2}$ (Springer et al. 2003) e incrementando la densidad poblacional de tallos del segundo, tercer y cuarto año se reportan valores de 80, 166 y 100 tallos $\mathrm{m}^{2}$ (Mashingo et al. 2008). El pasto zacatón alcalino [Sporobolus airoides (Torr.) Torr.] según NRCS
(2012) y Cox (1984) es un pasto $C_{4}$ dehiscente que se distribuye desde el sureste de Arizona, Centro de Texas y Norte de México con altura de 30 a $90 \mathrm{~cm}$ con la característica particular de crecer con $20 \mathrm{~mm}$ de lluvia en primavera, cuando otros pastos perennes están dormantes y llega a madurez fisiológica con 200 $\mathrm{mm}$ de lluvia con producción de forraje de 2360 a $5230 \mathrm{~kg} \mathrm{MS} \mathrm{ha}^{-1}$ y producción de semilla de 300 $\mathrm{kg} \mathrm{ha}^{-1}$. Lo que indica que los recursos forrajeros existentes en Norteamérica son de importancia para mejorar la ganadería tanto para temporal como riego.

El conocimiento del peso de tallos de una pradera proporciona una referencia esencial para el manejo, donde el peso individual de cada tallo con sus componentes morfológicos representa el comportamiento productivo de una pradera (Gastal y Lamaire 2015). La evaluación de calidad de semilla de pastos está dada por la evaluación física y fisiológica, principalmente (Hernández-Guzmán et al. 2015) donde las unidades de dispersión en switchgrass y pasto salado son diásporas, mientras en pasto maicero son cúpulas. En México la investigación de pastos forrajeros como switchgrass, pasto maicero y zacatón alcalino a latitud Norte menor de $20^{\circ}$ a más de 2000 msnm es escasa. También, se tiene necesidad de dar a conocer forrajes alternativos de poca disposición de humedad para rumiantes en el Valle de Tulancingo. Por lo anterior, el objetivo del estudio fue evaluar en el primer año de establecimiento la producción de forraje, composición morfológica, dinámica de tallos, producción y calidad de semillas de switchgrass (Panicum virgatum), pasto maicero (Tripsacum dactyloides) y zacatón alcalino (Sporobolus airoides), con riego por goteo.

\section{MATERIALES Y MÉTODOS}

\section{Descripción del sitio experimental}

El estudio se realizó en Ahuehuetitla, Tulancingo de Bravo, Hidalgo, México a $20^{\circ} 0505 \mathrm{LN}$ y $98^{\circ} 2451 \mathrm{LO}$, a $2172 \mathrm{msnm}$. El lugar tiene clima templado semihúmedo con temperatura media anual de $16{ }^{\circ} \mathrm{C}$. El suelo del lugar es de tipo vertisol de textura arcillosa (INEGI 2009). El establecimiento de switchgrass, pasto maicero y zacatón alcalino fue realizado 
el 22 de abril de 2020 a partir de tallos con raíces vivas de plantas adultas en suelo saturado. Los datos mensuales de precipitación y temperaturas media promedio durante el periodo experimental, se obtuvieron de la Dirección de Protección Civil-bomberos de Tulancingo ubicada a $1500 \mathrm{~m}$ del área experimental (Figura 1).

\section{Preparación de terreno y origen de los pastos}

Antes del trasplante, el terreno se preparó con barbecho y dos pasos de rastra, se surcó a distancia de $1.2 \mathrm{~m}$, con meseta de $50 \mathrm{~cm}$, después, se colocó cintilla de goteo con capacidad de $10 \mathrm{~L}$ por hora y se cubrió con plástico (acolchado). Cada pasto de su lugar de origen, fue extraído a $30 \mathrm{~cm}$ del suelo, después, las plantas fueron colocadas en macetas (40 cm diámetro $\times 40 \mathrm{~cm}$ de alto) para su transporte, e inmediatamente la parte aérea se cortó a $10 \mathrm{~cm}$ de forraje residual y se agregó suelo del lugar de modo de no exponer raíces al viento o radiación solar. Las plantas de switchgrass se colectaron el 15 de abril de 2020 en Rio Verde, San Luis Potosí, México $\left(21^{\circ} 52\right.$ $49 \mathrm{LN}$ y $100^{\circ} 0125 \mathrm{LO}$ ), a $1004 \mathrm{msnm}$. Las plantas de zacatón alcalino se colectaron el 17 de abril de 2020 en Soledad de Graciano Sánchez, San Luis Potosí, México (2214 $17 \mathrm{LN}$ y $100^{\circ} 5120$ LO), a 1838 msnm. Mientras que las plantas de pasto maicero se colectaron el 20 de abril de 2020 en Jaltepec, Tulancingo de Bravo, Hidalgo, México ( $20^{\circ} 0621 \mathrm{LN}$ y $98^{\circ} 2514$ LO) a 2174 msnm.

\section{Manejo de las parcelas, diseño}

Cada unidad experimental constó de dos sur$\cos (2.4 \mathrm{~m})$ por $5 \mathrm{~m}$ de largo con capacidad para 10 plantas en $12 \mathrm{~m}^{2}$, con $90 \mathrm{~cm}$ de distancia entre plantas por línea a densidad de 8333 plantas $\mathrm{ha}^{-1}$. El diseño fue en bloques completamente al azar con tres repeticiones, donde una planta se consideró como unidad experimental. Se regó cinco días antes de trasplantar con $30 \mathrm{~mm}$ de lámina de agua para llevar el suelo a capacidad de campo, y al terminar nuevamente se regó con otros $30 \mathrm{~mm}$ de agua distribuidos en 10 días para asegurar el establecimiento, posteriormente se regó a 15 y 30 días después del trasplante con $30 \mathrm{~mm}$ por fecha y por último el 15 y 30 de julio con $20 \mathrm{~mm}$ por fecha (en cada fecha, la cantidad de agua se distribuyó en 10 días). Posteriormente el riego ya no fue utilizado, y se dependió totalmente de la precipitación pluvial, ya que se consideró exitoso el establecimiento. No se fertilizó y no se observaron plagas que disminuyeran la producción de forraje y semilla.

\section{Variables evaluadas}

Se evaluaron dos ciclos productivos, de abril a agosto, y de agosto a diciembre de 2020. El corte de uniformización se realizó el 21 de mayo de 2020 para el primer ciclo y 20 de agosto para el segundo ciclo. Se midió altura de planta $(\mathrm{cm})$, en cuatro plantas homogéneas de cada unidad experimental con un flexómetro desde nivel del suelo hasta la altura máxima de planta (ya fuese hoja o inflorescencia) y se dejó de medir al presentar madurez fisiológica. Para el grosor de corona $(\mathrm{cm})$, se midió el diámetro en la parte basal de cuatro plantas por unidad experimental con vernier a madurez fisiológica cuando llegó a su altura máxima. El intervalo de medición para altura de planta y diámetro de corona fue cada 14 días a partir del 4 de junio al 6 de agosto y del 20 de agosto al 19 noviembre, para tener seis muestreos por ciclo.

La composición morfológica (g MS planta ${ }^{-1}$ ) y producción de forraje $\left(\mathrm{kg} \mathrm{MS} \mathrm{ha}^{-1}\right)$, se determinó a 90 días después de trasplante cuando las tres especies de pasto mostraban antesis en la mitad de tallos florales. Para lo cual se defoliaron cuatro plantas de cada parcela a $20 \mathrm{~cm}$ sobre el suelo y fueron separados los componentes morfológicos (hojas, tallos, inflorescencias y material muerto) por ciclo, los cuales fueron colocados en bolsas de papel previamente rotuladas. Posteriormente se dispusieron al ambiente con techo durante 14 días y después durante $48 \mathrm{~h}$ en una estufa de aire forzado Marca Ciderta ${ }^{\circledR}$ (Huelva, España) a $55^{\circ} \mathrm{C}$ e inmediatamente se pesó en una báscula marca Hanchen y modelo BSM220.4 (Pekin, $0.0001 \mathrm{~g}$ ). La producción de forraje $\left(\mathrm{kg} \mathrm{MS} \mathrm{ha}^{-1}\right)$ fue la suma de los componentes morfológicos. Para lo cual se multiplicó el promedio de las cuatro plantas por parcela de los tres bloques por la capacidad de establecer 8333 plantas por hectárea. 


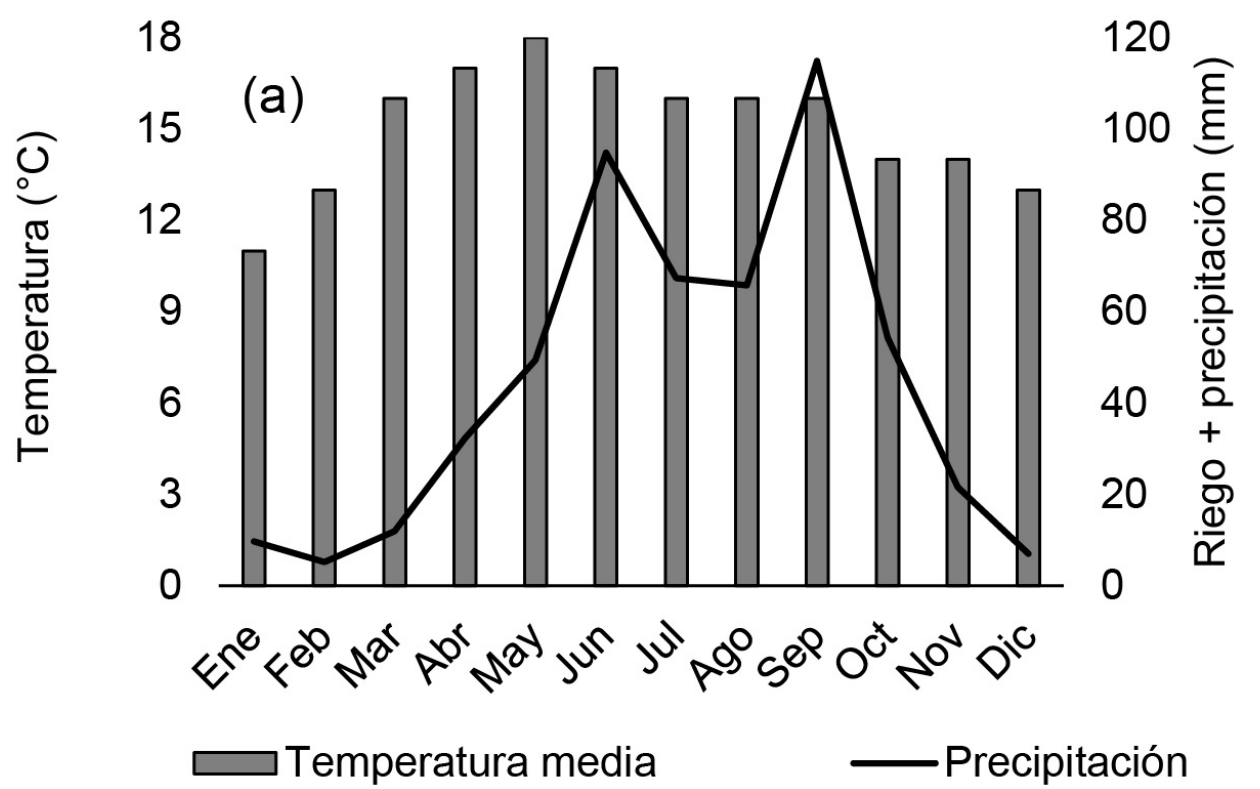

Figura 1. Condiciones climatológicas de precipitación + riego y temperatura promedio en Tulancingo de Bravo, Hidalgo, durante el periodo experimental.

Proporción hoja:tallo. Se calculó al dividir el peso de las hojas (g) entre el peso de los tallos (g). Tallos florales planta ${ }^{-1}$, se dererminó en cuatro plantas destinadas a evaluar la producción de semilla, donde se contabilizaron los tallos florales con inflorescencia excerta en cada ciclo. Densidad poblacional de tallos, se realizó en dos plantas por unidad experimental, para lo cual los tallos presentes de cada planta se consideraron como población inicial. Posteriormente, cada 30 días, de abril a diciembre, los tallos emergidos se marcaron con anillos de diferente color y se registraron, y los tallos muertos se contaron y se les retiró el anillo, los cuales fueron restados a la densidad de tallos del mes correspondiente.

Producción de semilla $\left(\mathrm{kg} \mathrm{ha}^{-1}\right)$. Las fechas de colecta de semillas de pasto switchgrass fueron el 14 de agosto y 20 de octubre. Las semillas de zacatón alcalino fueron colectadas el 16 de agosto y 10 de noviembre y las semillas de pasto maicero el 15 de agosto y 13 de noviembre. La producción de semilla fue realizada en cuatro plantas de cada unidad experimental, y dependiendo del cambio de coloración de cada especie, en switchgrass cuando las inflorescencias tornaron de rojo intenso a rojo tenue y las glumas de morado a beige claro. En za- catón alcalino cuando las flores tornaron de verde a beige, mientras en pasto maicero fue cuando el androceo tornó a café claro y $10 \%$ de dehiscencia del androceo (aproximadamente) y el gineceo de verde a verde claro-beige. Las inflorescencias de las tres especies se dispusieron sobre papel estrasa de $1 \times 1 \mathrm{~m}$ previamente rotuladas en un invernadero con flujo de aire durante 14 días. Posteriormente, las unidades de dispersión fueron separadas de manera manual (switchgrass y zacatón) a partir de las inflorescencias y en caso de pasto maicero se eliminó el androceo, para después separar las cúpulas entre sí. Después de 12 días se iniciaron la pruebas de humedad de las semillas con un probador de humedad marca LDS$1 G$ con Pantalla LCD (Pekín) hasta que registraron $12-13 \%$ humedad constante.

\section{Rendimiento de semilla, análisis físico y fisiológico}

Pureza física de semillas o llenado (\%). Para obtener cariópsides a partir de diásporas, fueron pesadas cuatro repeticiones de $3 \mathrm{~g}$, después se usó un tapete y almohadilla de caucho corrugado con fricción manual para separar a cariópsides, y posteriormente colocar en cajas Petri y pesar. En el caso de las cúpu- 
las de pasto maicero se usaron pinzas manuales para verificar la existencia de cariópside por cada cúpula, para lo cual se tomaron 500 cúpulas en cuatro repeticiones, ya que su llenado fue incipiente. Cariópsides ( $\mathrm{kg} \mathrm{ha}^{-1}$ ); se homogenizó la semilla por especie de ambas fechas de colecta en un contenedor plástico, para obtener cariópsides en switchgrass y zacatón alcalino, fueron pesadas cuatro repeticiones de 3 gramos y para obtener cariópsides, se usó fricción manual con la ayuda de tapete y caucho corrugado; el resultado se reporta en kilogramos de cariópside a partir del total de unidades de dispersión completas (diásporas). Para el pasto maicero, se pesaron $20 \mathrm{~g}$ de cúpulas en cuatro repeticiones, y cuando se encontraron cariópsides se pesaron en una báscula marca Hanchen y modelo BSM220.4 (Pekin, 0.0001 g).

Peso de mil cariópsides. Se contaron ocho repeticiones de 100 semillas botánicas y el promedio se multiplicó x 10 (Hernández-Guzmán et al. 2015). En caso de pasto maicero se usaron cuatro repeticiones de 15 cariópsides por escasez de semillas botánicas y se pesó en báscula marca Hanchen y modelo BSM220.4 (Pekin, $0.0001 \mathrm{~g}$ ). Viabilidad. La viabilidad se determinó de acuerdo a la metodología empleada por Hernández-Guzmán et al. (2015), la cual consistió en humedecer a cariópsides durante $6 \mathrm{~h}$, posteriormente, se cortaron semillas de manera longitudinal con ayuda de microscopio estereoscópico, de modo que se expusieron los tejidos embrionarios al tetrazolio al $0.1 \%$ durante $12 \mathrm{~h}$ a la sombra. La clasificación de viabilidad fue de acuerdo a la intensidad de color; de incoloro a rosa pálido $=$ no viables, de rosa a rojo intenso = viables. Semilla pura viable $\left(\mathrm{kg} \mathrm{ha}^{-1}\right)$. Se determinó mediante la relación de la cantidad de semilla pura en una hectárea multiplicado por el porcentaje de viabilidad con tetrazolio. Para evaluar las variables de laboratorio se usó un diseño completamente al azar. Los datos de campo y laboratorio se analizaron con GLM de SAS (2004). La comparación de medias de todos tratamientos se efectuó mediante la prueba de Tukey, con un nivel de significancia del $5 \%$.

\section{RESULTADOS}

En el primer ciclo de evaluación switchgrass (Panicum virgatum) mostró similitudes estadísticas con pasto maicero (Tripsacum dactyloides) $(\mathrm{P}>0.05$, Figura 2a), mientras que zacatón alcalino (Sporobolus airoides) mostró alturas menores por fecha ( $p$ $<0.001$ ). En el ciclo 2 (Figura $2 b$ ) pasto maicero destacó por mostrar mayor altura y su crecimiento no disminuyó pese a la disminución de temperatura $(P$ $<0.001$, Figura 1), mientras switchgrass y zacatón alcalino mostraron similitudes estadísticas y fueron afectados por la aproximación al invierno. Para la altura en el primer ciclo, el pasto zacatón alcalino tuvo menor altura en comparación con switchgrass y pasto maicero $(\mathrm{P}<0.0001$, Figura $2 \mathrm{a})$, pero en el segundo ciclo la altura del pasto maicero fue mayor $(\mathrm{P}<$ 0.0001 ) y ésta no fue afectada por la disminución de las temperaturas de otoño (Figura 2b).

En producción de forraje, el pasto switchgrass destacó por producir mayor cantidad de forraje en la suma de los dos ciclos, en comparación a pasto maicero y zacatón alcalino en 5.5 y 9.5 veces, dadas las condiciones de humedad constante, sin fertilización y altura sobre el nivel del mar (Tabla 1), por tanto, en el primer año de establecimiento, el pasto menos productivo es zacatón alcalino. La producción de forraje disminuyó en switchgrass al segundo ciclo en 2.0 veces, mientras pasto maicero y zacatón alcalino incrementaron en 1.6 y 1.8 veces, por tanto, switchgrass es más forrajero dadas las condiciones climáticas.

En cuanto a composición morfológica se observaron diferencias significativas en los tres pastos estudiados $(P<0.0001$, Tabla 1$)$. La mayor cantidad de hojas fue en switchgrass en primer, segundo ciclo y suma de éstos $(P<0.0001)$, y superó ampliamente a pasto maicero y zacatón alcalino en 5.5 y 8.2 veces, sin embargo, en hoja:tallo fue inverso, donde zacatón alcalino siempre mostró valor mayor $(\mathrm{P}<$ 0.0001 ), por tanto, a mayor producción de biomasa forrajera menor proporción de hoja. En peso de inflorescencias, en el primer ciclo switchgrass produjo mayor cantidad y en segundo ciclo pasto maicero ( $P$ $<0.0001$ ), mientras zacatón alcalino siempre mostró 

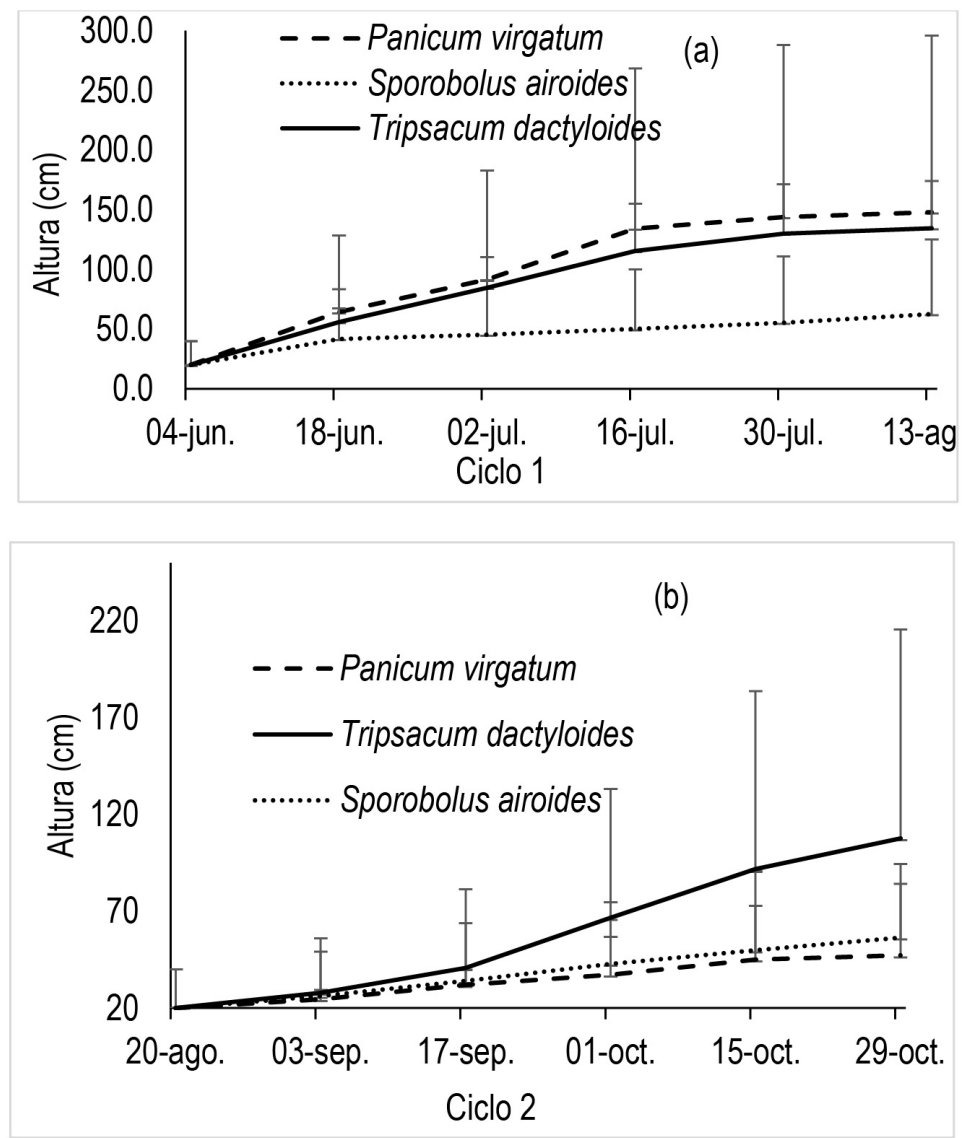

Figura 2. Altura de planta de switchgrass (Panicum virgatum), pasto maicero (Tripsacum dactyloides) y zacatón alcalino (Sporobolus airoides), registrada hasta madurez fisiológica en dos ciclos en Tulancingo de Bravo, Hidalgo, establecidos el 22 de abril 2020 en condiciones por goteo. a) primer ciclo y b) segundo ciclo.

menor cantidad $(P<0.0001)$ lo cual se comporta de igual manera en el número de tallos florales, por tanto, en los tres pastos estudiados, un indicador de peso de inflorescencias es el número de tallos florales. La presencia de material muerto es mínima debido a aparición de tallos en las tres especies, ya que las plantas fueron defoliadas cuando presentaban antesis en $50 \%$ de tallos florales. En cuanto al diámetro de corona, se observaron diferencias en cada fecha de muestreo en los tres pastos, así como entre especie $(P<0.0001$, Tabla 1$)$, de modo que, desde la lectura inicial a la final, en switchgrass, pasto maicero y zacatón alcalino, el incremento promedio fue 14, 8.0 y $10 \mathrm{~cm}$, respectivamente, por tanto, en el primer año de establecimiento el incremento fue constante.

La densidad de población de tallos en los tres pastos estudiados incrementó cada 30 días de manera constante y se observaron diferencias en aparición de tallos, tallos muertos y tallos presentes planta $^{-1}(P<0.0001$, Tabla 2). El incremento de tallos en la primera fecha respecto a la última en switchgrass, pasto maicero y zacatón alcalino fue 9.0, 21.6 y 10.0 veces, respectivamente, ya que eran nuevos macollos en crecimiento sin haber llegado a edad fisiológica madura. La mortalidad de tallos en las tres especies fue mayor desde octubre, noviembre y diciembre $(P<0.0001)$, ya que son pastos $\mathrm{C}_{4}$. La vida productiva de los tallos es alta en las tres especies de pasto estudiadas, en promedio los tallos por especie de pasto, sobrevivió el 97.0, 95.6 y $90.4 \%$ para switchgrass, pasto maicero y zacatón alcalino, respectivamente, ya que las plantas siempre 
Tabla 1. Rendimiento de materia seca ( $\mathrm{kg} \mathrm{MS} \mathrm{ha}^{-1}$ ), composición morfológica ( $\mathrm{g} \mathrm{MS} \mathrm{planta}{ }^{-1}$ ), tallos florales (cantidad planta ${ }^{-1}$ ) y diámetro de corona $(\mathrm{cm})$ en tres pastos nativos forrajeros mexicanos, establecidos en Tulancingo, Hidalgo, México.

\begin{tabular}{|c|c|c|c|c|c|c|c|c|c|}
\hline \multirow[b]{2}{*}{ Especie } & \multicolumn{4}{|c|}{ g MS planta } & \multirow{2}{*}{$\mathrm{kg} \mathrm{MS} \mathrm{ha}^{-1}$} & \multirow{2}{*}{$\begin{array}{l}\text { No tallos } \\
\text { florales }\end{array}$} & \multirow{2}{*}{ hoja:tallo } & \multirow{2}{*}{$\begin{array}{c}\text { Diámetro } \\
\text { corona i }\end{array}$} & \multirow{2}{*}{$\begin{array}{c}\text { Diámetro } \\
\text { corona } f\end{array}$} \\
\hline & Hojas & Tallos & Infl & $\mathrm{mm}$ & & & & & \\
\hline \multicolumn{10}{|c|}{ Primer ciclo } \\
\hline Swithgrass (Panicum virgatum) & $128^{a^{\dagger}}$ & $146^{a}$ & $13^{a}$ & $2.0^{a}$ & $2411^{a}$ & $21^{a}$ & $0.88^{b}$ & $8.9^{a}$ & $18^{a}$ \\
\hline Pasto maicero (Tripsacum dactyloides) & $23^{b}$ & $26^{b}$ & $2.2^{b}$ & $1.0^{b}$ & $434^{b}$ & $17^{b}$ & $0.93^{b}$ & $6.8^{b}$ & $11^{b}$ \\
\hline Zacatón alcalino (Sporobolus airoides) & $16^{b}$ & $14^{b}$ & $0.7^{b}$ & $0.4^{c}$ & $252^{b}$ & $2.0^{c}$ & $1.28^{a}$ & $3.6^{c}$ & $10^{c}$ \\
\hline Promedio & 56 & 62 & 5.3 & 1.1 & 1033 & 13.33 & 1.03 & 6.4 & 13 \\
\hline EEM & 3.25 & 3.55 & 0.58 & 0.096 & 58.09 & 1.15 & 0.076 & 0.26 & 0.32 \\
\hline Significancia & $* \star \star$ & 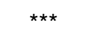 & 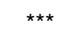 & $\star \star \star ~$ & *** & $* * *$ & ** & $* \star \star$ & $* * *$ \\
\hline \multicolumn{10}{|c|}{ Segundo ciclo } \\
\hline Swithgrass (Panicum virgatum) & $74^{a}$ & $59^{a}$ & $5.5^{b}$ & $2.2^{b}$ & $1173^{a}$ & $34^{a}$ & $1.25^{a}$ & $20^{a}$ & $30^{a}$ \\
\hline Pasto maicero (Tripsacum dactyloides) & $42^{b}$ & $30^{b}$ & $11.3^{a}$ & $3.7^{a}$ & $725^{b}$ & $22^{b}$ & $1.41^{a}$ & $13^{b}$ & $21^{b}$ \\
\hline Zacatón alcalino (Sporobolus airoides) & $23^{c}$ & $25^{b}$ & $7.5^{b}$ & $0.7^{c}$ & $467^{c}$ & $9.0^{c}$ & $1.56^{a}$ & $11^{c}$ & $17^{c}$ \\
\hline Promedio & 46 & 38 & 8.1 & 2.2 & 788 & 22 & 1.41 & 15 & 23 \\
\hline EEM & 3.00 & 4.43 & 0.66 & 0.30 & 0.57 & 1.380 & 0.138 & 0.32 & 0.32 \\
\hline Significancia & 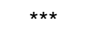 & 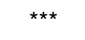 & 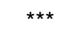 & 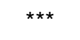 & 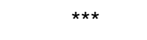 & $* \star \star$ & NS & *** & $* \star \star$ \\
\hline \multicolumn{7}{|c|}{ Suma de los dos ciclos } & \multicolumn{3}{|l|}{ Promedio } \\
\hline Swithgrass (Panicum virgatum) & $202^{a}$ & $205^{a}$ & $19^{a}$ & $4.2^{a}$ & $3584^{a}$ & $55^{a}$ & $1.1^{b}$ & & \\
\hline Pasto maicero (Tripsacum dactyloides) & $65^{b}$ & $56^{b}$ & $13^{b}$ & $4.7^{a}$ & $1159^{b}$ & $39^{b}$ & $1.2^{a b}$ & & \\
\hline Zacatón alcalino (Sporobolus airoides) & $39^{c}$ & $39^{b}$ & $8^{c}$ & $1.1^{b}$ & $720^{c}$ & $11^{c}$ & $1.4^{a}$ & & \\
\hline Promedio & 102 & 100 & 13 & 3 & 1821 & 35 & 1.2 & & \\
\hline EEM & 3.76 & 5.16 & 0.85 & 0.306 & 71.64 & 2.42 & 0.75 & & \\
\hline Significancia & 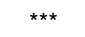 & *** & *** & 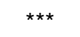 & 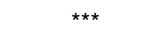 & *** & ** & & \\
\hline
\end{tabular}

Tabla 2. Aparición, muerte y tallos presentes planta $^{-1}$ de tres pastos nativos forrajeros mexicanos establecidos mediante trasplante de tallos a partir de plantas adultas en riego por goteo en Tulancingo de Bravo, Hidalgo, México.

\begin{tabular}{|c|c|c|c|c|c|c|c|c|}
\hline Concepto & mayo & junio & julio & agosto & septiembre & octubre & noviembre & diciembre \\
\hline \multicolumn{9}{|c|}{ Aparición de tallos planta $^{-1}$} \\
\hline Switchgrass (Panicum virgatum) & $21^{a \dagger}$ & $43^{a}$ & $65^{a}$ & $84^{a}$ & $106^{a}$ & $127^{a}$ & $160^{a}$ & $193^{b}$ \\
\hline Pasto maicero (Tripsacum dactyloides) & $10.4^{b}$ & $22^{b}$ & $42^{b}$ & $61^{b}$ & $80^{b}$ & $108^{b}$ & $157^{a}$ & $226^{a}$ \\
\hline Zacatón alcalino (Sporobolus airoides) & $9.0^{b}$ & $20^{b}$ & $34^{b}$ & $43^{c}$ & $52^{c}$ & $60^{c}$ & $74^{b}$ & $91^{c}$ \\
\hline Promedio & 14 & 28 & 47 & 62 & 79 & 98 & 130 & 170 \\
\hline Significancia & 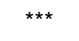 & *** & *** & *** & *** & *** & *** & *** \\
\hline EEM & 0.92 & 1.67 & 2.54 & 2.81 & 3.11 & 3.85 & 4.89 & 6.66 \\
\hline \multicolumn{9}{|c|}{ Muerte de tallos planta $^{-1}$} \\
\hline Switchgrass (Panicum virgatum) & & $1.1^{a}$ & $0.9^{a}$ & $0.9^{a}$ & $0.9^{a}$ & $1.0^{a}$ & $0.8^{c}$ & $5.8^{b}$ \\
\hline Pasto maicero (Tripsacum dactyloides) & & $0.4^{b}$ & $0.9^{a}$ & $0.8^{a}$ & $0.8^{a}$ & $0.9^{a}$ & $2.2^{b}$ & $9.9^{a}$ \\
\hline Zacatón alcalino (Sporobolus airoides) & & $0.0^{c}$ & $0.1^{b}$ & $0.0^{b}$ & $0.1^{b}$ & $0.5^{a}$ & $3.3^{a}$ & $8.8^{a}$ \\
\hline Promedio & & 0 & 0.6 & 0.6 & 0.6 & 0.8 & 2.1 & 8.1 \\
\hline Significancia & & 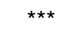 & *** & *** & *** & ** & *** & *** \\
\hline EEM & & 0.101 & 0.11 & 0.09 & 0.112 & 0.149 & 0.305 & 0.53 \\
\hline \multicolumn{9}{|c|}{ Tallos presentes planta ${ }^{-1}$} \\
\hline Switchgrass (Panicum virgatum) & $21^{a}$ & $42^{a}$ & $64^{a}$ & $83^{a}$ & $105^{a}$ & $126^{a}$ & $159^{a}$ & $187^{b}$ \\
\hline Pasto maicero (Tripsacum dactyloides) & $10^{b}$ & $22^{b}$ & $41^{b}$ & $60^{b}$ & $80^{b}$ & $107^{b}$ & $155^{a}$ & $216^{a}$ \\
\hline Zacatón alcalino (Sporobolus airoides) & $9.0^{b}$ & $20^{b}$ & $34^{b}$ & $43^{c}$ & $52^{c}$ & $59^{c}$ & $70^{b}$ & $82^{c}$ \\
\hline Promedio & 14 & 28 & 47 & 62 & 79 & 98 & 128 & 162 \\
\hline Significancia & *** & *** & *** & *** & *** & *** & *** & *** \\
\hline EEM & 0.92 & 1.67 & 2.56 & 2.79 & 3.11 & 3.86 & 4.89 & 6.64 \\
\hline
\end{tabular}

Error estándar de la media.

tuvieron humedad y no hubo presencia de plagas o enfermedades que repercutieran en disminuir la vida de los tallos.
Se observaron diferencias significativas en rendimiento de semilla, análisis físico y fisiológico en los tres pastos estudiados en ambos ciclos ( $P$ 
$<0.0001$, Tabla 3). En los tres pastos se registró mayor cantidad de semilla en el segundo ciclo en comparación al primero para cada pasto $(P<0.01)$, ya que hubo mayor cantidad de tallos florales, porque el diámetro de corona fue mayor a mayor edad de las plantas $(P<0.0001)$ lo cual influyó en mayor cantidad de semilla. Al sumar la producción de ambos ciclos, hubo similitud estadística entre switchgrass y pasto maicero en la suma de ambos ciclos $(P>$ 0.05), sin embargo, en pasto maicero se observó llenado de cúpulas de manera incipiente (pureza física) en ambos ciclos $(P<0.0001)$ lo que hace que su rendimiento de cariópsides sea pobre $(P<0.0001)$ aunado a baja viabilidad $(P<0.0001)$, por tanto, baja cantidad de semilla pura viable ha ${ }^{-1}$; así que para la multiplicación de éste genotipo tendrá que ser por material vegetal.

La pureza física o llenado (\%) fue mayor en zacatón alcalino en ambos ciclos $(P<0.0001)$ seguido de switchgrass, por tanto, baja producción de semilla en zacatón alcalino es compensada con mayor llenado y con mayor cantidad de semilla pura viable por hectárea. Así mismo se observó disminución de llenado en el segundo ciclo en una unidad porcentual de los tres pastos $(P<0.05)$. En peso de mil cariópsides, se observó que semillas botánicas de pasto maicero son de mayor peso $(P<0.0001)$ por características propias de la especie, mientras que switchgrass y zacatón alcalino tienen diferente peso $(P<0.0001)$, lo cual es importante para escribir protocolos en establecimiento en campo o invernadero. La viabilidad fue diferente en las tres especies de pasto estudiadas $(P<0.0001)$, y se observó menor viabilidad en el segundo ciclo en las tres especies a mayor peso de cariópsides. Por lo anterior, iniciar el rebrote en las primeras semanas después de primavera será importante para no incidir antesis en el segundo ciclo aproximado al mes de noviembre, de modo que repercuta en semilla pura viable.

\section{DISCUSIÓN}

La altura de planta de los tres pastos en el primer año establecidos en Tulancingo, Hidalgo, en swichgrass $(150 \mathrm{~cm})$ está en el rango mencionado por
Taylor et al. (2019), así como zacatón alcalino (50 $\mathrm{cm}$; NRCS 2012) y pasto maicero (1.2 m, Shadow 2012), por lo que la altura sobre el nivel del mar no afectó la altura de los pastos estudiados, ya que la precipitación, temperatura, radiación y tipo de metabolismo $\left(\mathrm{C}_{4}\right)$ son los factores principales que afectan los patrones de distribución altitudinal en pastos (Giraldo-Cañas 2010). La producción de forraje así como la altura de pasto maicero no disminuyó en aproximación a finales de otoño, lo cual es reportado por Mason et al. (2019) en enero (575 kg MS ha-1) y febrero $\left(715 \mathrm{~kg} \mathrm{MS} \mathrm{ha}^{-1}\right)$. Por otro lado, switchgrass reduce su productividad al final de la estación de crecimiento a menores temperaturas y se prepara para hibernar (Parrish y Fike 2005).

La producción de forraje de los dos ciclos de producción en el primer año de producción, para switchgrass ( $3584 \mathrm{~kg} \mathrm{MS} \mathrm{ha}^{-1}$ ) y pasto maicero (1 $159 \mathrm{~kg} \mathrm{MS} \mathrm{ha}^{-1}$ ), están en el rango mencionado por Marra et al. (2013) y Mason et al. (2019), respectivamente. Por otro lado, en zacatón alcalino (720 kg MS ha ${ }^{-1}$ ) fue inferior a lo reportado por Cox (1984) y NRCS (2012), pero no hay reportes en el primer año de establecimiento. La producción de forraje en switchgrass no fue afectada a los $1168 \mathrm{~m}$ de diferencia con su lugar de origen (Río Verde, SLP, México), al respecto GiraldoCañas (2010) y Grabowski et al. (2014) mencionan que la mayor plasticidad genética (ploidía) permite mayor adaptabilidad, mientras que Coblentz et al. (2010) reportan que en éste pasto la producción es más afectada por longitud, por lo que no se debe desplazar más de $500 \mathrm{~km}$ de su lugar de origen. En tanto que Tornqvist et al. (2017) mencionan que los genotipos de switchgrass originarios de tierras bajas son de porte alto con tallos fuertes que permiten altos rendimientos de forraje, y por tanto redituable en ganadería, por lo que el Departamento de Energía de E.U. declaró a switchgrass como un cultivo redituable para generación de biocombustibles. Por lo que México, como un centro de origen importante de recursos genéticos de especies de Poaceae para zonas áridas y semiáridas, tiene la oportunidad de desarrollar tecnología para incrementar la resiliencia social, y así evitar la migración (Quero-Carrillo et 
Tabla 3. Rendimiento de semilla ( $\mathrm{kg} \mathrm{MS} \mathrm{ha}^{-1}$ ), análisis físico y fisiológico (\%) y semilla pura viable $\mathrm{ha}^{-1}(\mathrm{~kg})$ de tres pastos nativos forrajeros mexicanos en Tulancingo de Bravo, Hidalgo, México.

\begin{tabular}{|c|c|c|c|c|c|c|c|c|c|c|c|}
\hline \multirow{2}{*}{ Pasto } & $\begin{array}{l}\text { Primer } \\
\text { ciclo }\end{array}$ & $\begin{array}{l}\text { Segundo } \\
\text { ciclo }\end{array}$ & \multirow{2}{*}{$\begin{array}{l}\text { Suma de ambos } \\
\text { ciclos de } \\
\text { producción de } \\
\text { semilla ha }^{-1}\end{array}$} & $\begin{array}{l}\text { Primer } \\
\text { ciclo }\end{array}$ & $\begin{array}{l}\text { Segundo } \\
\text { ciclo }\end{array}$ & \multirow{2}{*}{$\begin{array}{c}\text { Semillas } \\
\text { botánicas } \\
(\mathrm{kg})\end{array}$} & $\begin{array}{l}\text { Primer } \\
\text { ciclo }\end{array}$ & $\begin{array}{l}\text { Segundo } \\
\text { ciclo }\end{array}$ & $\begin{array}{l}\text { Primer } \\
\text { ciclo }\end{array}$ & $\begin{array}{l}\text { Segundo } \\
\text { ciclo }\end{array}$ & \multirow{2}{*}{$\begin{array}{c}\text { Semilla } \\
\text { pura } \\
\text { viable } \\
\mathrm{ha}^{-1}(\mathrm{~kg})\end{array}$} \\
\hline & \multicolumn{2}{|c|}{$\begin{array}{l}\mathrm{kg} \mathrm{semilla}_{\mathrm{ha}^{-1}}\end{array}$} & & \multicolumn{2}{|c|}{$\begin{array}{c}\text { Pureza física } \\
(\%)\end{array}$} & & \multicolumn{2}{|c|}{$\begin{array}{c}\text { Peso de mil } \\
\text { cariópsides }(\mathrm{mg})\end{array}$} & \multicolumn{2}{|c|}{$\begin{array}{c}\text { Viabilidad } \\
(\%)\end{array}$} & \\
\hline Switchgrass (Panicum virgatum) & $54.6^{a A \dagger}$ & $92.6^{a B}$ & $147.1^{a}$ & $8.26^{b A}$ & $7.20^{b A}$ & $10.65^{a}$ & $0.915^{b A}$ & $0.881^{b A}$ & $85.6^{b A}$ & $85.4^{a A}$ & $9.1^{a}$ \\
\hline Pasto maicero (Tripsacum dactyloides) & $66.7^{a A}$ & $110.6^{a B}$ & $177.2^{a}$ & $0.79^{c A}$ & $0.80^{c A}$ & $1.51^{b}$ & $5.684^{a A}$ & $5.340^{a A}$ & $66.2^{c A}$ & $64.9^{c A}$ & $1.0^{b}$ \\
\hline Zacatón alcalino (Sporobolus airoides) & $6.9^{b A}$ & $64.3^{b B}$ & $71.2^{b}$ & $22.70^{a A}$ & $20.81^{a A}$ & $14.08^{a}$ & $0.369^{c A}$ & $0.350^{c A}$ & $93.0^{a A}$ & $79.9^{b B}$ & $12.3^{a}$ \\
\hline Promedio & 42.7 & 89.1 & 131.9 & 10.6 & 9.6 & 8.7 & 2.323 & 2.190 & 81.6 & 76.7 & 7.4 \\
\hline significancia & 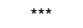 & $\star \star$ & 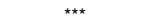 & 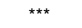 & 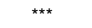 & $\star \star \star$ & 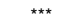 & 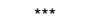 & 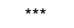 & 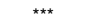 & 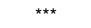 \\
\hline EEM & 9.5 & 8.09 & 12.38 & 0.498 & 0.467 & 1.21 & 0.129 & 0.162 & 1.40 & 1.39 & 1.02 \\
\hline
\end{tabular}

${ }^{\dagger}$ letras minúsculas iguales por columna y letras mayúsculas iguales por línea son promedios estadísticamente similares $(P>0.05) .{ }^{* \star} P<0.001,{ }^{\star \star \star} P<$ 0.0001. EEM = Error estándar de la media.

al. 2017).

El número de tallos florales en switchgrass fue similar a lo reportado por Jhonson et al. (2017) con $22 \pm 1$ tallos florales planta ${ }^{-1}$, sobre lo mismo Boe (2007) reportó correlación positiva entre el número de tallos florales con la producción de forraje y semilla, por tanto, a mayor número de tallos florales, mayor producción de unidades de dispersión. Por otro lado, en pasto maicero, Mashingo et al. (2008) relaciona de forma lineal el número de tallos florales con la cantidad de forraje y fecha de cosecha. En cuanto al diámetro de corona, en switchgrass y pasto maicero los valores se encuentran dentro del rango reportado por Springer et al. (2003) y Taylor et al. (2019). En una corona en expansión, los rebrotes nuevos son emergidos alrededor de la corona, los cuales en un inicio son débiles, pero la disponibilidad de nutrientes es menor que al centro de la corona; lo que ocasiona mayor rebrote hasta un equilibrio en la planta completa. Sobre lo mismo Springer et al. (2003) comentan que posterior a dos años de establecidos el pasto maicero, el diámetro de la corona se estabiliza, lo cual fue sustentado por Quero-Carrillo et al. (2016) para pastos como banderita y navajita, y por Elbersen et al. (2013) en switchgrass.

Para la densidad poblacional de tallos de pasto maicero los valores encontrados se encuentran dentro de los rangos reportados por Springer et al. (2003), sin embargo, en el switchgrass potosino se comparó con los genotipos evaluados por Min et al. (2017) y éste es ampliamente superior en amacollar en 6.0 veces a seis meses de muestreo. Sobre lo mismo Waramit et al. (2014) reportan que la densidad de tallos de switchgrass en la variedad Cave In Rock, incrementan conforme avanza el ciclo pro- ductivo, pero al final, los primeros son renovados casi en totalidad, mientras en el genotipo mexicano, los tallos tienen más vida productiva. También para el pasto maicero, variedad Pete se reportan que incrementa durante el ciclo productivo, pero al final, persiste similar cantidad de 600 tallos $\mathrm{m}^{2}$ (Huang et al. 2016), mientras que el genotipo tulancinguense incrementa cada 30 días su población. La densidad de tallos de zacatón alcalino (82 tallos $\mathrm{m}^{2}$ ) fue mayor a lo reportado por Sebade y Mealor (2012), los cuales fueron de 3.0 a 6.2 tallos planta $^{-1}$ en el primer año, lo que indica que el genotipo colectado en Soledad de Graciano Sánchez, San Luis Potosí, México, amacolla en mayor cantidad que genotipos de Wyoming, E.U. En los tres pastos se observó que los tallos registrados en la primera fecha persisten hasta la última, por tal motivo no se encontró abundante material muerto, ya que la aparición de tallos y baja mortalidad de los mismos trajo consigo nuevas hojas que incrementan la cantidad de peso por planta, como fue consignado por Gastal y Lamaire (2015).

El rendimiento de semilla o unidades de dispersión en la suma de los dos ciclos $\left(\mathrm{kg} \mathrm{ha}^{-1}\right)$ fue similar en switchgrass y pasto maicero, pero en el segundo se tiene pureza física incipiente (llenado) comparado con el reporte de Ahring y Frank (1968) en semillas de $T$. dactyloides de un genotipo local de Dakota del Sur, E.U., la cual osciló de 33 a 89\%. El rendimiento de semilla de swicthgrass es similar a lo reportado por Boe (2007) y Lee et al. (2009), a pesar de ser el primer ciclo año. Lo cual indica que el genotipo colectado en Río Verde, San Luis Potosí, México, es de gran valor forrajero y de semillas. La pureza física fue mayor en zacatón alcalino, por tanto, dadas las condiciones de suelo y clima, esta especie tiene 
mayor porcentaje de llenado a lo largo de la panícula y los cariópsides llegan a madurez con embrión y endospermo en buen estado.

El peso de 1000 semillas botánicas, en switchgrass es similar en tres de 16 genotipos reportado por Elbertsen et al. (2013) con pesos de 940, 850 y 900 mg. Para pasto maicero, el peso de 1000 semillas fue inferior a lo reportado por Huang et al. (2016), en la variedad Pete, esto es $24 \mathrm{~g}$. El porcentaje de viabilidad de cariópsides de switchgrass colectado en San Luis Potosí, México, en primer (85.6) y segundo ciclo (85.4) fue similar a Kimura et al. (2015) en dos lotes de switchgrass (94 y $85 \%$ ) posterior a la cosecha, lo que hace que sea una especie con buen vigor según Hernández-Guzmán et al. (2015), ya que cariópsides medianos de pasto banderita y cariópsides grandes de pasto rhodes mostraron valores de 90 y $87 \%$ de viabilidad.

Por otro lado, en pasto maicero, la viabilidad de los cariópsides reportada por Huang et al. (2016) fue del $65 \%$, valor similar al genotipo evolucionado en Tulancingo, al respecto se sabe que la viabilidad de semillas botánicas de pastos es afectada desde cosecha y almacenamiento y disminuye debido a la peroxidación de los ácidos grasos insaturados, daño a membranas y DNA (Kimura et al. 2015). En la cosecha (mecánica o manual) debe cuidarse en gran medida que las semillas o inflorescencias no suden, ya que éste fenómeno disminuye la viabilidad del embrión en coleorriza y/o plúmula del embrión y por tanto, disminuye el vigor, lo que se refleja en menor germinación y disminución de la velocidad de germinación (Quero-Carrillo et al. 2017).

La cantidad de semilla pura viable cosechada en Tulancingo, Hidalgo, México, en switchgrass, permite sembrar de 1.0 a 2.0 ha de acuerdo a Elbersen et al. (2013) con densidad de siembra de 5 a 15 $\mathrm{kg}$ de semilla pura viable aunque hay que tomar en cuenta que las semillas presentan latencia, ya que según Cortese y Bonos (2012) en condiciones de laboratorio de 483 semillas sembradas germinaron sobre papel 123 (25\%) y llegan a madurez 56 . Por otro lado, en zacatón alcalino, la densidad de siembra según NRCS (2012) es de $500 \mathrm{~g}$ de semilla pura viable, lo que cual permite sembrar 19.6 ha.

\section{CONCLUSIONES}

En el primer año de establecimiento en Tulancingo, Hidalgo, la producción mayor de forraje y cantidad de hojas se observó en switchgrass, seguido de pasto maicero y zacatón alcalino. La densidad poblacional de tallos fue importante para generar inflorescencias. El pasto maicero tiene llenado incipiente en las cúpulas, el cual deberá multiplicarse por material vegetal. La viabilidad fue menor a mayor peso de semilla botánica. El pasto zacatón alcalino produce mayor cantidad de semilla pura viable, pero produce menos cantidad de forraje.

\section{LITERATURA CITADA}

Ahring RM, Frank H (1968) Establishment of eastern gamagrass from seed and vegetative propagation. Journal Range Management 21: 27-30.

Ayala-Garay AV, Schwentesius-Rindermann R, de la O-Olán M, Preciado-Rangel P, Almaguer-Vargas G, RivasValencia $P$ (2013) Análisis de rentabilidad de la producción de maíz en la región de Tulancingo, Hidalgo, México. Agricultura, Sociedad y Desarrollo 10: 381-395.

Berti MT, Johnson BL (2013) Switchgrass establishment as affected by seeding depth and soil type. Industrial Crops and Products 41: 289-293.

Boe A (2007) Variation between two switchgrass cultivars for components of vegetative and seed biomass. Crop Science 43: 636-642.

Coblentz WK, Jokela WE, Hoffman PC, Bertra MG (2010) Unique dairy applications of eastern gamagrass forages in Central Wisconsin: I. Yield potential. Agronomy Journal 102: 1710-1719. 
Cortese LM, Bonos SA (2012) Bioenergy traits of ten switchgrass populations grown in the Northeastern / MidAtlantic USA. BioEnergy Research 6: 580-590.

Cox JR (1984) Shoot production and biomass transfer of big sacaton [Sporobolus wrightii]. Journal of Range Management 37: 377-380.

Dávila AP, Mejía-Saulés MT, Gómez-Sánchez M, Valdés-Reyna J, Ortiz JJ, Morín C, Castrejón J, Ocampo A (2006) Catálogo de gramíneas de México. Universidad Nacional Autónoma de México/Comisión Nacional para el Conocimiento y Uso de la Biodiversidad. México. 671p.

Elbersen HW, Poppens R, Bakker R (2013) Switchgrass (Panicum virgatum L.). A perennial biomass grass for efficient production of feedstock for the biobased economy. A report for the Netherlands Programmes Sustainable Biomass of NL Agency. The Netherlands. 28p.

Gastal F, Lemaire G (2015) Defoliation, shoot plasticity, sward structure and herbage utilization in pasture: Review of the underlying ecophysiological processes. Agriculture 5: 1146-1171.

Giraldo-Cañas $\mathrm{D}$ (2010) Distribución e invasión de gramíneas $\mathrm{C}_{3}$ y $\mathrm{C}_{4}$ (Poaceae) en un gradiente altitudinal de los Andes de Colombia. Caldasia 32: 65-86.

Grabowski PP, Morris GP, Casler MD, Borevitz JO (2014) Population genomic variation reveals roles of history, adaptation and ploidy in switchgrass. Molecular Ecology 23: 4059- 4073.

Hernández-Guzmán FJ, Quero-Carrillo AR, Pérez-Rodríguez P, Velázquez-Martínez M, García-de los Santos G (2015) Germinación y emergencia de propágulos de pasto, en respuesta a pruebas de vigor. Revista Mexicana de Ciencias Agrícolas 6: 1519-1532.

Huang W, Wang D, Taylor AG (2016) Seed pressing to remove cupules and obtain caryopses in eastern gamagrass. Seed Science and Technology 44: 114-124.

INEGI (2009) Prontuario de información geográfica municipal de los Estados Unidos Mexicanos. Tulancingo de Bravo, Hidalgo. Instituto Nacional de Estadística, Geografía e Informática. México. 9p.

Johnson CR, Millwood RJ, Tang Y (2017) Field-grown miR156 transgenic switchgrass reproduction, yield, global gene expression analysis, and bioconfinement. Biotechnol Biofuels 10: 255: DOI: 10.1186/s13068-0170939-1.

Krizek DT, Ritchie JC, Sadeghi AM, Foy CD, Rhoden EG, Davis JR, Camp MJ (2003) A four-year study of biomass production of eastern gamagrass grown on an acid compact soil. Communications in Soil Science and Plant Analysis 34: 457-480.

Kimura E, Fransen SC, Collins HP, Guy SO, Johnston WJ (2015) Breaking seed dormancy of switchgrass (Panicum virgatum L.): A review. Biomass and Bioenergy 80: 94-101.

Lee D, Owens VN, Boe A, Koo B (2009) Biomass and seed yields of big bluestem, switchgrass, and intermediate wheatgrass in response to manure and harvest timing at two topographic positions GCB. Bioenergy 1: 171179.

Marra M, Keene T, Skousen J, Griggs T (2013) Switchgrass yield on reclaimed surface mines for bioenergy production. Journal of Environment Quality 42: 696-703.

Mashingo MSH, Kellogg DW, Coblentz WK, Anschutz KS (2008) Effect of harvest dates on yield and nutritive value of eastern gamagrass. The Professional Animal Scientist 24: 363-373.

Mason KM, Mullenix MK, Tucker JJ, Muntifering RB, Angle JS, Yeager J (2019) Overseeding eastern gamagrass with cool-season annual grasses or grass - legume mixtures. Crop Science 59: 2264 -2270. 
Min D, Guragain YN, Prasad V, Vadlani PV, Lee J (2017) Effects of different genotypes of switchgrass as a bioenergy crop on yield components and bioconversion potential. Journal of Sustainable Bioenergy Systems 7: $27-35$

NRCS (2012) 'Saltalk' Alkali Sacaton Sporobolus airoides (Torr.) Torr. Natural Resources Conservation Service Unites States Department of Agriculture. A Conservation Plant Release by USDA NRCS James E. "Bud". Smith Plant Materials Center, Knox City, TX. https://www.nrcs.usda.gov/Internet/FSE_PLANTMATERIALS/ publications/txpmcrb11558.pdf. Fecha de consulta: 30 de diciembre de 2020.

Parrish DJ, Fike JH (2005) The biology and agronomy of switchgrass for biofuels. Critical Reviews in Plant Sciences 24: 423-459.

Quero-Carrillo AR, Hernández-Guzmán FJ, Pérez-Rodríguez P, Pool D, Landa-Salgado P, Nieto-Aquino R (2017) Germinación y emergencia diaria de cariópsides y diásporas de pastos nativos e introducidos. Revista Fitotecnia Mexicana 40: 35-44.

Quero-Carrillo AR, Hernández-Guzmán FJ, Velázquez-Martínez M, Gámez-Vázquez HG, Landa-Salgado P y Aguilar-López P (2016) Métodos de establecimiento de pasturas en zonas áridas de México utilizando semillas crudas o cariópsides. Tropical grasslands - Forrajes Tropicales 4: 29-37.

Ra K, Shiotsu F, Abe J, Morita S (2012) Biomass yield and nitrogen use efficiency of cellulosic energy crops for ethanol production. Biomass and Bioenergy 37: 330-334.

SAS (2004) SAS/STAT R 9.1 user's guide. SAS Publishing. SAS Institute Inc., NC, USA. 5121p.

Sebade BM, Hild AL, Mealor BA (2012) Native Grasses Collected from Invasions Demonstrate Invasion Resistance. Ecological Restoration 30: 209-217.

Shadow RA (2012) Plant fact sheet for Eastern Gamagrass (Tripsacum dactyloides). USDA-Natural Resources Conservation Service, Plant Materials Center. Nacogdoches, TX 75964. 2p. https://www.nrcs.usda.gov/ Internet/FSE_PLANTMATERIALS/publications/etpmcfs11219.pdf Fecha de consulta: 20 de diciembre de 2020.

Springer TL, Dewald CL, Sims PL, Gillen R L (2003) How does plant population density affect the forage yield of eastern gamagrass? Crop Science 43: 2206 - 2211.

Taylor M, Tornqvist CE, Zhao X, Doerge RW, Casler MD, Jiang Y (2019) Identification of quantitative trait loci for plant height, crown diameter, and plant biomass in a pseudo- $F_{2}$ population of Switchgrass. Bioenergy Research 12: 267-274.

Tornqvist CE, Vaillancourt B, Kim J, Buell CR, Kaeppler SM, Casler MD (2017) Transcriptional analysis of flowering time in Switchgrass. BioEnergy Research 10: 700-713

Velázquez MM, Hernández GFJ, Cervantes BJF, Gámez VHG (2015) Establecimiento de pastos nativos e introducidos en zonas semiáridas de México. Folleto para Productores No. MX-0-310307-52-03-17-1066 Centro de Investigación Regional del Noreste Campo Experimental San Luis, San Luis Potosí. 36p. http://www.inifapcirne.gob.mx/Biblioteca/Publicaciones/998.pdf Fecha de consulta: 30 de noviembre de 2020.

Waramit N, Moore KJ, Heaton E (2014) Nitrogen and harvest date affect developmental morphology and biomass yield of warm-season grasses. GCB Bioenergy 6: 534-543. 